\title{
PERFORMANCE OF DIRECT INJECTION C.I. ENGINE USING KARANJA OIL AT DIFFERENT INJECTION PRESSURES
}

\author{
A.G. Matani ${ }^{1}$, Mukesh A. Mane ${ }^{2}$ \\ ${ }^{1}$ Associate Professor, Mechanical Engineering, ${ }^{2}$ M.Tech, II Year, Thermal Engineering, Government College of \\ Engineering, Amravati, - 444604 (M.S.) India
}

\begin{abstract}
Use of biodiesel as an alternative to diesel could reduce the dependency on petroleum product and the pollution problems. Increasing injection pressure is beneficial for achieving better atomization which will directly increase the surface area of injected fuel. In this paper the performance of different blends such as 10B (10\% neat Karanja oil and 90\% diesel), 20B, 30B, 40B and 100\% diesel compared at different injection pressure 150bar, 170bar, 190bar and 210bar.It is found that as the injection pressure increases the brake thermal efficiency (BTE), also increases and brake specific fuel consumption (BSFC) is lowered as the injection pressure is increases. In the present work, experiments are conducted on $3.72 \mathrm{~kW}(5 \mathrm{BHP})$ single cylinder, four stroke, air-cooled diesel engine using neat Karanja oil blended with diesel in various proportions to study the engine performance.
\end{abstract}

Keywords: Neat Karanja oil, brake thermal efficiency, brake specific fuel consumption, Injection pressure ****

\section{INTRODUCTION}

The increasing industrialization \& motorization of the world lead to a steep rise in the demand of diesel products and these are limited reserves. The increasing petroleum price and environmental concern due to global warming has developed the thrust in search of renewable fuels for diesel engines. Recently, much attention has been paid to the development of alternative fuels in order to meet the emission standards and to reduce the dependency on fossil fuel. Especially, neat vegetable oil and their biodiesels have been considered as major alternative fuels, as they are derived from renewable sources. These fuels are well oxygenated and therefore have a great potential to reduce emissions.

Since pure vegetable oil is not suitable as fuel for diesel engines they have to be modified to bring their combustion related properties closer to diesel. This fuel modification eliminates flow/ atomization related problems. Four techniques can be used to reduce the viscosity of vegetable oil are as follows:-

[1] Heating

[2] Transesterification with alcohol

[3] Blending with diesel or alcohol

[4] Micro-emulsion

In this paper, blending with diesel techniques is used nonedible Karanja oil and its blends is used as fuel for $\mathrm{CI}$ engines. The blend 10B , 20B 30B and 40B are used as fuels their performance is tested at different injection pressures of 150bar ,170bar,190bar and 210bar, BTE and BSFC values are calculated and the graphs are plotted at different pressures and different loads.

\section{EXPERIMENTAL SET UP}

The experimental set up as shown in Figure 1 is used for the work. In which wire brake rope drum is used to apply the load at different pressures, the electrical panel is used to show the EGT and the RPM of engine. By using burette the mass flow rate is measured. The engine used for this experiment is as shown below:-

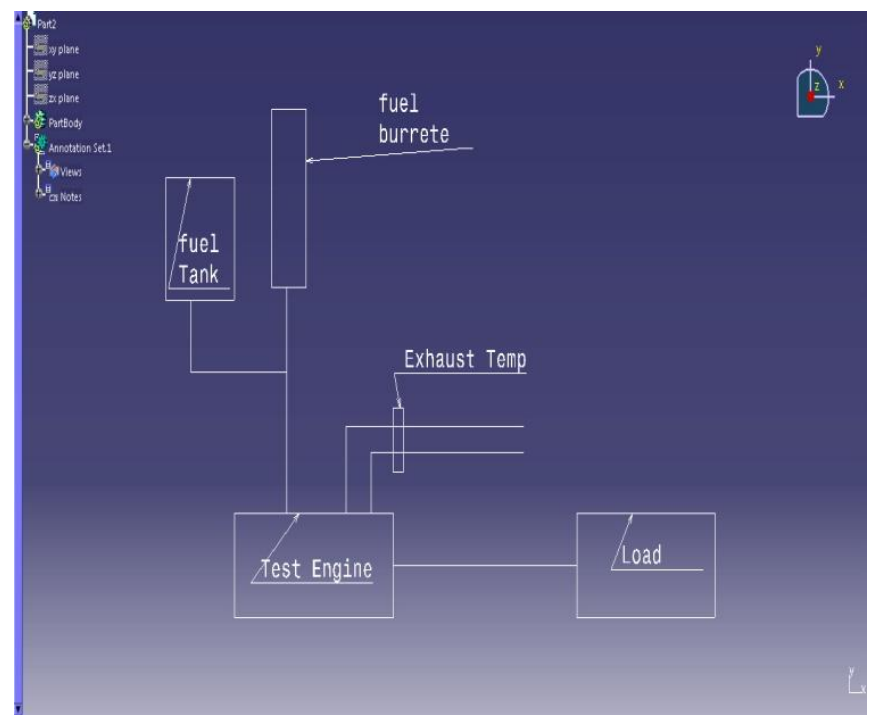

Fig.1: Schematic diagram of experimental set up 


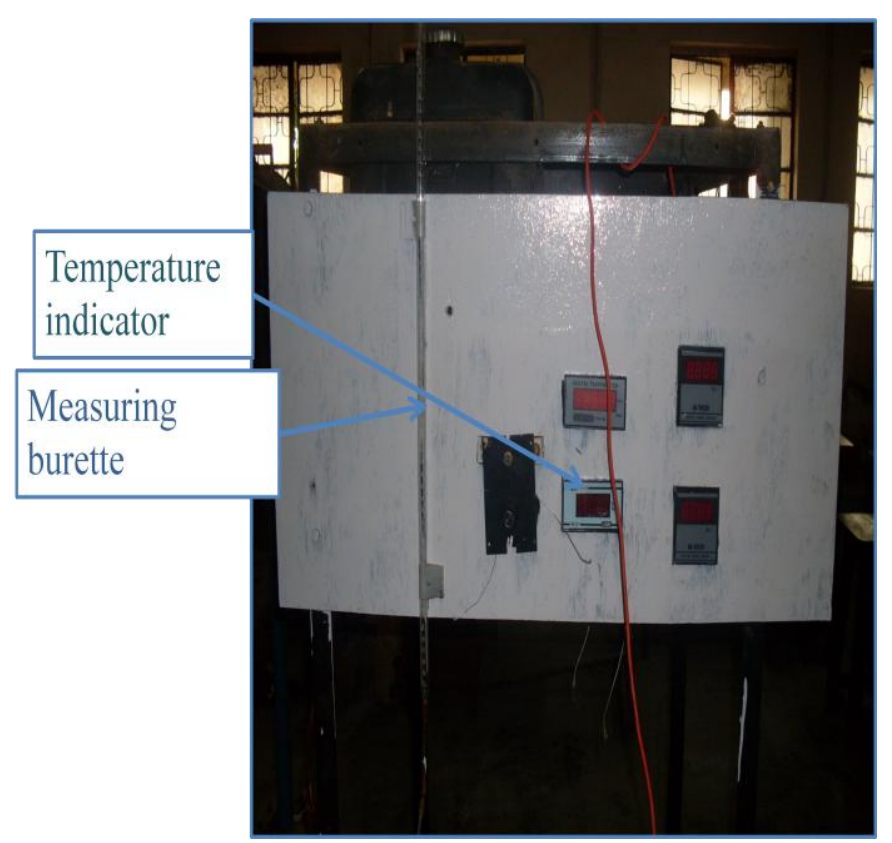

Fig .2: Control panel

Table 1-Specifications of Engine

\begin{tabular}{|c|c|c|c|}
\hline $\begin{array}{l}\text { Sr. } \\
\text { No }\end{array}$ & Component & Unit & Description \\
\hline 1 & $\begin{array}{l}\text { Name of the } \\
\text { engine }\end{array}$ & & $\begin{array}{ll}\text { Kirloskar } & \text { Oil } \\
\text { Engine } & \\
\end{array}$ \\
\hline 2 & Type of engine & - & $\begin{array}{l}\text { Four stroke } \\
\text { single cylinder } \\
\text { CI engine }\end{array}$ \\
\hline 3 & No. of cylinder & - & 1 \\
\hline 4 & $\begin{array}{l}\text { IS Rating at } 1500 \\
\text { rpm }\end{array}$ & $\mathrm{kW}(\mathrm{bhp})$ & $3.7(5.0)$ \\
\hline 5 & Bore & MM & 80 \\
\hline 6 & Stroke & MM & 110 \\
\hline 7 & $\begin{array}{l}\text { Compression } \\
\text { Ratio }\end{array}$ & MM & $17.5: 1$ \\
\hline 8 & $\begin{array}{l}\text { Method of } \\
\text { cooling }\end{array}$ & - & Air \\
\hline
\end{tabular}

The fuel used in experiment is the blends of neat Karanja oil and diesel, and their performance with diesel fuel is measured.

\section{RESULTS AND DISCUSSIONS}

Result shows the performance of different blends, i.e., 10B, 20B, 30B, 40B and diesel at different injection pressure

\subsection{Performance of Blends at 150 Bars}

\subsubsection{BTE VS LOAD}

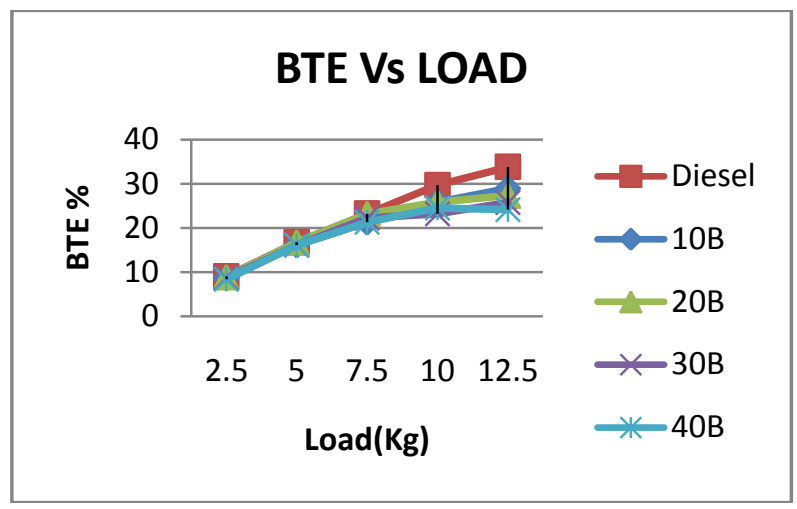

Fig- 3: BTE Vs LOAD at 150 Bar

Figur-3 shows the variation of the brake thermal efficiency at different engine load condition for diesel fuel and Karanja

\subsubsection{BSFC Vs LOAD}

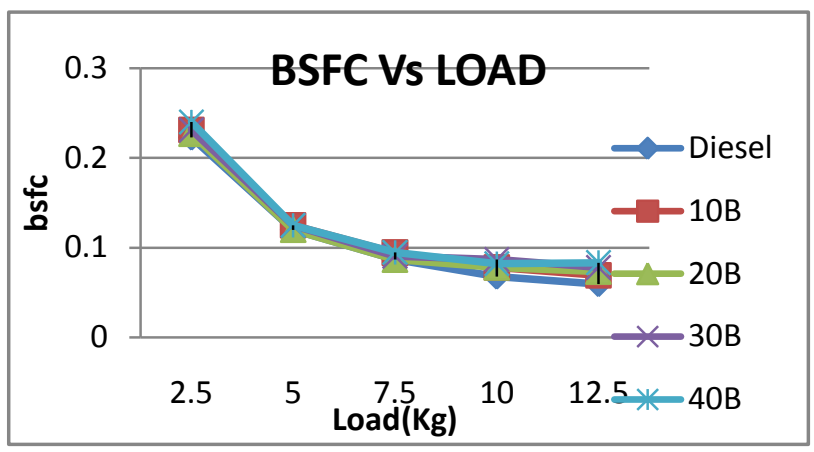

Fig -4: BSFC Vs LOAD at 150 Bar

Figure - 4 shows the variation of brake specific fuel consumption at different engine load condition. It can be observed from the figure that the BSFC for B-10 is nearer to that of diesel fuel

\subsubsection{EGT Vs LOAD}

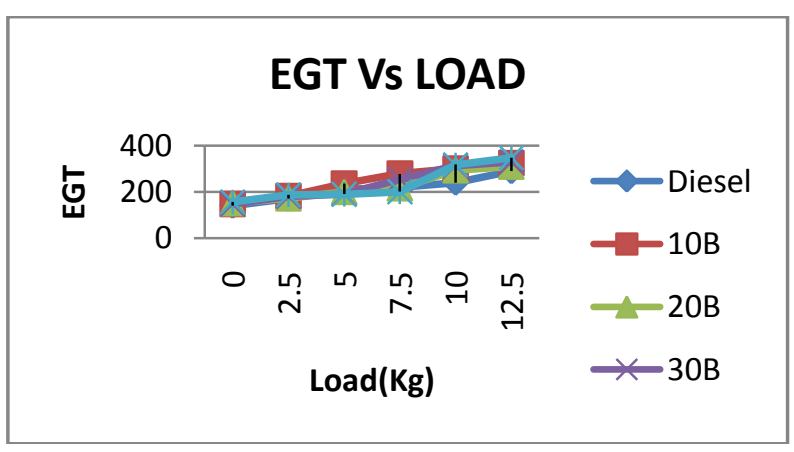

Fig -5- EGT Vs LOAD at150 Bar 
3.2 Performance of Blends at 170 Bars

\subsubsection{BTE Vs LOAD}

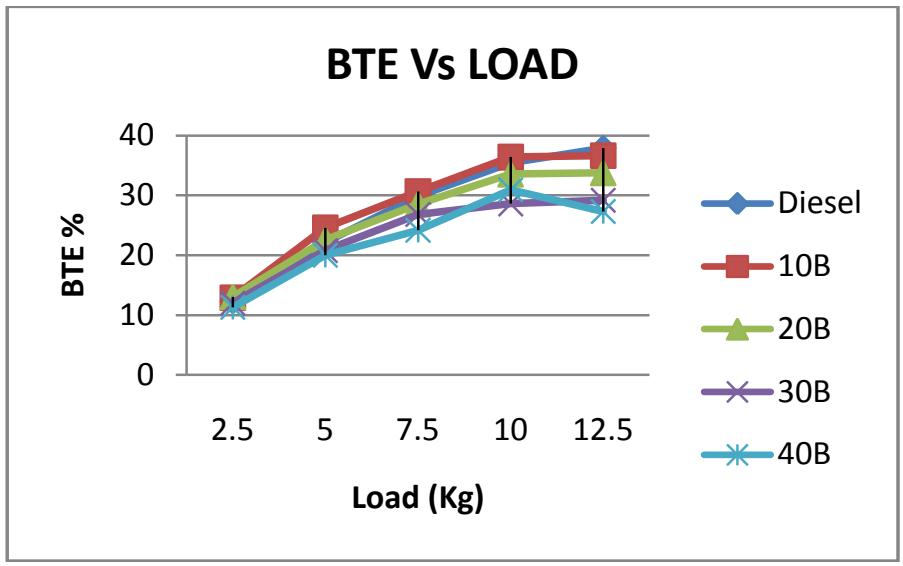

Fig- 6: BTE Vs LOAD at 170 Bar

\section{2) BSFC Vs LOAD}

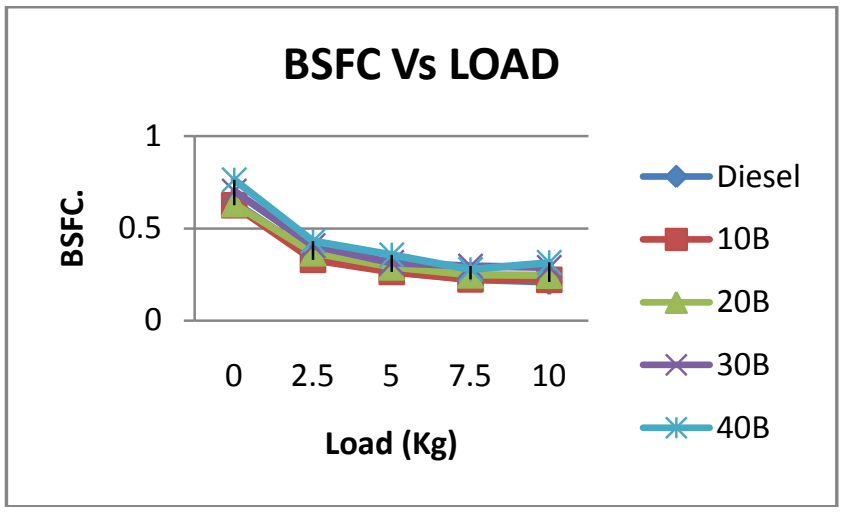

Fig- 7: BSFC Vs LOAD at 170 Bar

\section{3) EGT Vs LOAD}

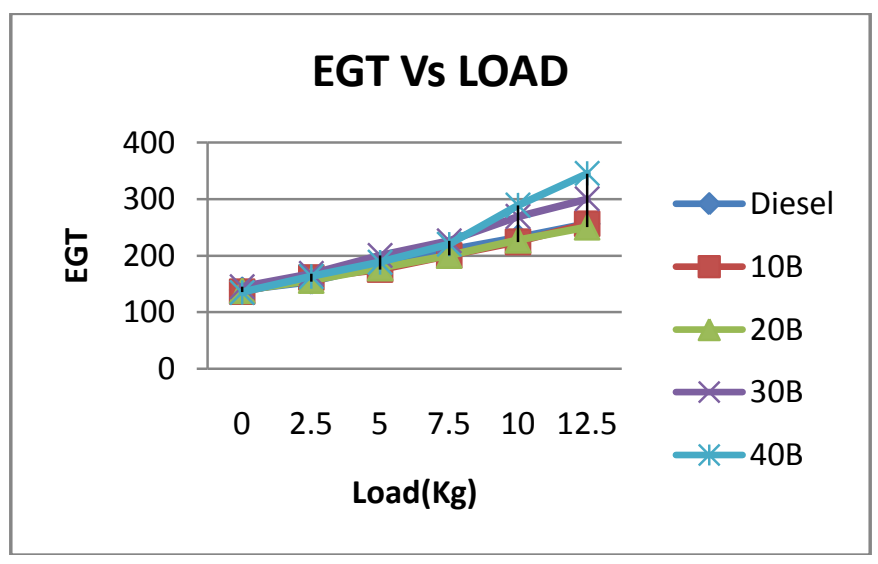

Fig-8: EGT Vs LOAD at 170 Bar

\subsection{Performance of Blends at 190 Bars}

\subsubsection{BTE Vs LOAD}

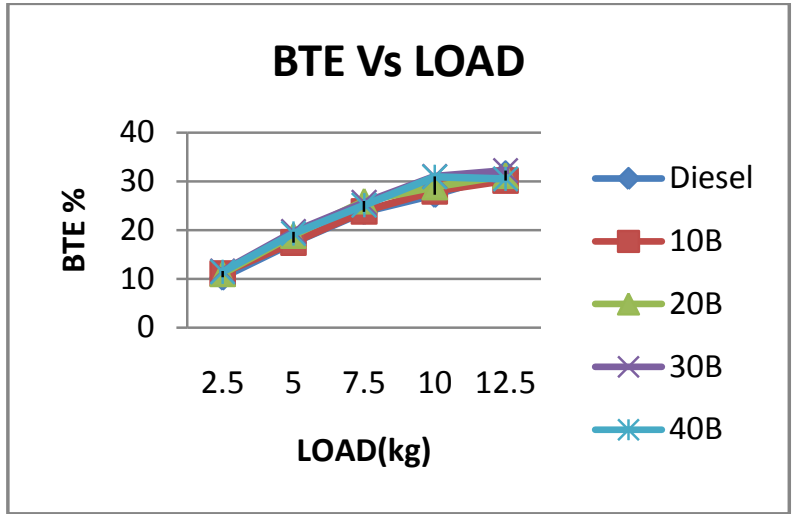

Fig- 9: BTE Vs LOAD at $190 \mathrm{Bar}$

At 190 bar the BTE of engine of blends $10 \mathrm{~B}$ and 20B get nearly equal to the BTE of diesel fuel without any modification in engine.

\subsubsection{BSFC Vs LOAD}

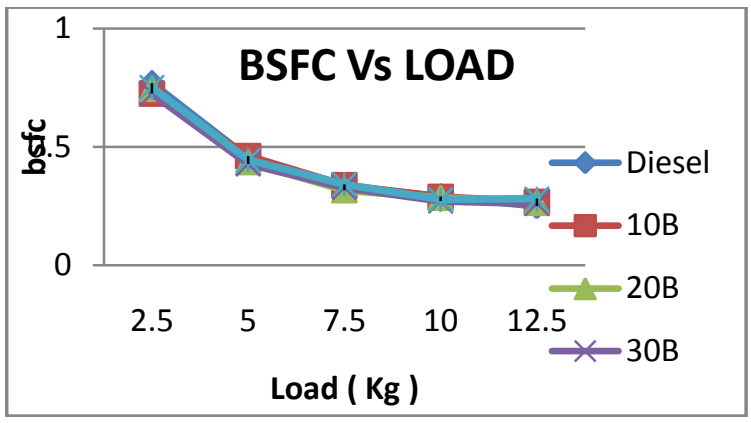

Fig-10: BSFC Vs LOAD at 190 Bar

At 190 bar the BSFC of engine of blends 10B and 20B get nearly equal to the BSFC of diesel fuel without any modification in engine.

\subsubsection{EGT Vs LOAD}

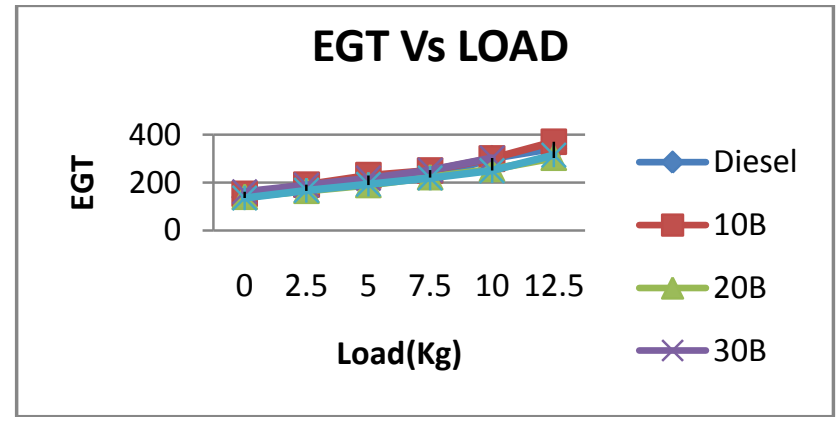

Fig- 11: EGT Vs LOAD at 190Bar 


\subsection{Performance of Blends at 210 Bars}

\subsubsection{BTE Vs LOAD}

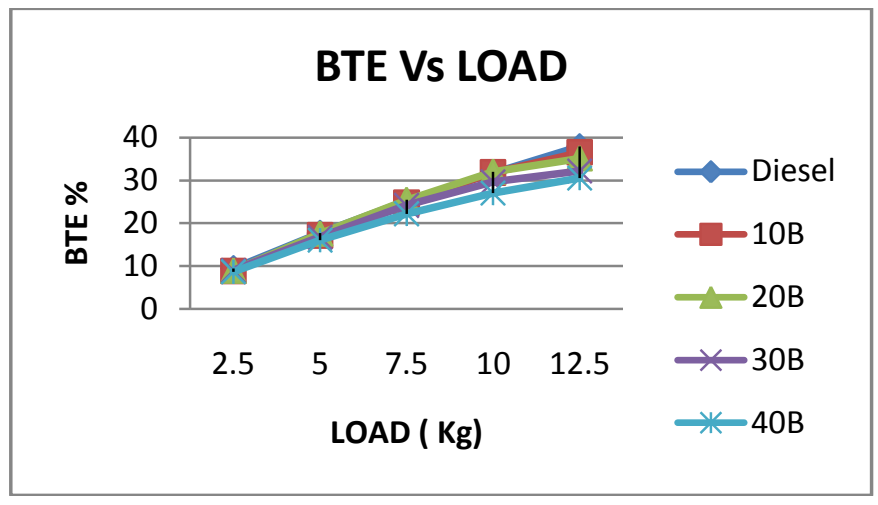

Fig: 12 BTE Vs LOAD at 210 Bar

BTE at 210 bar increases but vibration increased in engine and EGT also increases so some changes must be do in engine so we get the high performance

\subsubsection{BSFC Vs LOAD}

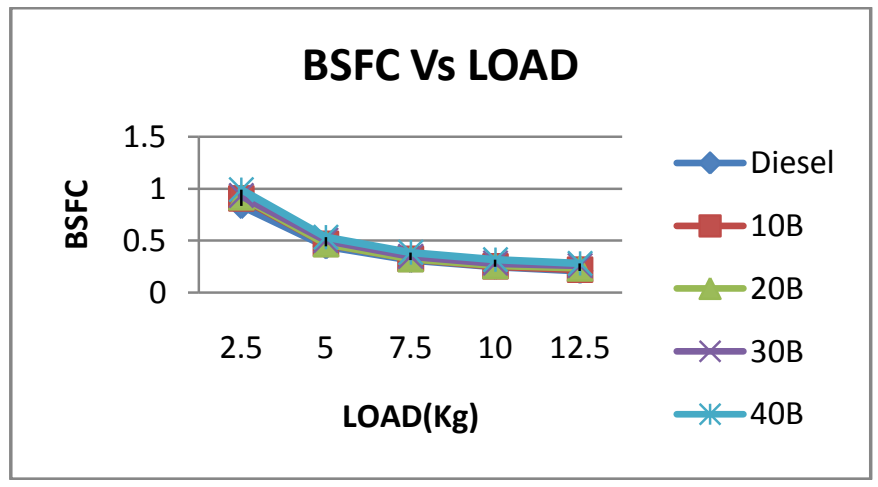

Fig: 13 BSFC Vs LOAD at 210 Bar

BSFC at 210 bar increases but vibration increased in engine and EGT also increases so some changes needs to be done in engine to achieve high performance.

\subsubsection{EGT Vs LOAD}

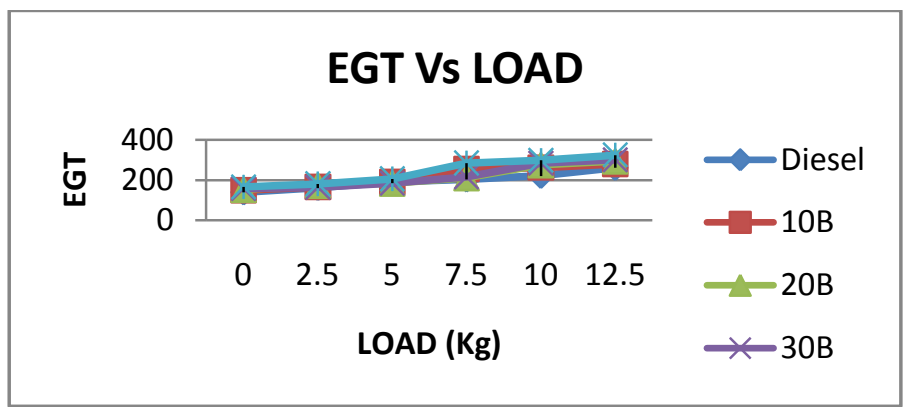

Fig- 14: EGT Vs LOAD at 210 Bar

\section{CONCLUSIONS}

From the results it shows that as the blends proportion increases the brake thermal efficiency decreases and brake specific fuel consumption increases. As the injection pressure increases the brake thermal efficiency also increases from which we can conclude that up to the $20 \%$ blend at 190 bar injection pressure can be used as alternative fuel for the direct injection C.I engine. Engine parameters such as brake specific fuel consumption, brake thermal efficiency are calculated, the results shows that the brake thermal efficiency of blends with diesel fuel is less as compared to diesel fuel. Fuel consumption is increased with increase in blend proportions. The test results indicates that biodiesel up to B-20 (20\% blend) can be used as an alternative without any modifications of diesel engine. Vegetable oils have the good potential to be considered as an appropriate alternative fuel as their properties are similar to that of diesel and their use in diesel engine reduces the harmful exhaust emission, particularly $\mathrm{HC}$ and $\mathrm{CO}$ as compared to diesel.

\section{REFERENCES}

[1]. A.S. Ramadhas, S. Jayaraj, C. Muraleedharan , (2004), Use of vegetable oils as I.C. engine fuels, Renewable Energy, Vol. 29 No.1, pp.727-742.

[2]. Avinash Kumar Agrawal, (2007), Bio fuels(alcohols and biodiesel) application as fuels for internal combustion engines, Progress in Energy and Combustion Science, Vol. 33, No. 2 , pp. 233-271.

[3]. Avinash Kumar Agrawal and K.Rajamanoharan,(2009), Experimental investigations of performance and emission of Kranja oil and its blend in a single cylinder diesel engine , Applied Energy, Vol. 86 ,No.2 ,pp.106-112.

[4]. Avinash Kumar Agarwal, Atul Dhar, (2013), Experimental investigations of performance, emission and combustion characteristics of Karanja oil blends fuelled DICI engine, Renewable Energy, Vol. 52 No.2,pp. 283-291.

[5]. B. Baiju, M.K. Naik, L.M. Das (2009), A comparative evaluation of compression ignition engine characteristics using methyl and ethyl esters of Karanja oil, Renewable Energy, Vol. 34 No. 2, pp. 1616-1621.

[6]. Dr. A.G. Matani, (2013), Effective energy conservation techniques in industries, International Journal of Mechanical Engineering \& Technology (IJMET), Vol. 4, No. 1,pp. 74 78

[8]. Dr. A.G. Matani, , (1999) , Managing new product innovations. Industrial Engineering Journal Vol. 4 No. 1, pp. 21-23.

[9]. Dr. A.G. Matani, (1998), Fly ash from TPS: Utilization \& disposal techniques, Research Journal of Chemistry \& Environment, Vol.3, No.1,pp. 71-73.

[10]. Dr. S.K. Doifode , Dr. A.G. Matani (2013), Advanced Environment Protection Techniques by Industries: Potential For Corporate Social Responsibility Activities, International Journal of Civil Engineering Vol. 7, No.2, pp. 14-18. 
[11]. M. V. Nagarhali, V. M. Nandenkar, K. C. Mohite, (2010), Emission and performance characteristics of Karanja biodiesel and its blends in a C.I engine and it's economics, ARPN Journal of Engineering and Applied Sciences, Vol. 5, No. 2, pp. 16-22.

[12]. Mustafa Balat and Havva Balat (2010), Progress in biodiesel processing, Applied Energy, Vol.87, No. 2, pp. 1885-1835.

[13]. S.Jindal, B.P. Nandawan, N.S, Rathore, V. Vashitha, (2010), Experimental investigation of the effect of compression ratio and injection pressure in a direct injection diesel engine running on Jatropha methyl ester, Applied Thermal Engineering, Vol. 30, No.2, pp.442-448. 